\title{
Fundamentação teórica no ensino de eletromagnetismo: uma revisão da literatura em periódicos nacionais ${ }^{+*}$
}

Daniel Trugillo Martins Fontes ${ }^{1}$

Mestre - Programa de Pós-Graduação Interunidades em Ensino de Ciências Universidade de São Paulo

São Paulo - SP

André Machado Rodrigues ${ }^{1}$

Universidade de São Paulo

São Paulo - SP

\section{Resumo}

Neste trabalho apresentamos uma revisão da literatura sobre a presença de referenciais teóricos dos diversos campos da educação e teorias da aprendizagem que orientam as publicações acerca do ensino de eletromagnetismo entre 2000 e 2019. Optamos por avaliar alguns periódicos nacionais na área de ensino de ciências ou ensino de física. Selecionamos os periódicos níveis A1 ou A2 nas áreas de avaliação de educação ou ensino na última classificação quadrienal da Qualis-Periódicos. A pesquisa resultou em uma amostra de 46 artigos, que foram organizados em termos de suas abordagens, a saber: utilização de experimentação, de tecnologias da informação e comunicação e de presença de referencial teórico. A nossa análise deu especial atenção aos artigos que apresentaram referencial teórico baseado na perspectiva da teoria históricocultural. Como resultado, encontramos 4 artigos que explicitamente se orientam segundo a teoria histórico-cultural no contexto do ensino de eletromagnetismo, discutindo o caráter motivador que atividades demonstrativas e investigativas podem propiciar, fazendo desse referencial uma interessante escolha para orientação e planejamento pedagógico no ensino de ciências. Ademais, notamos que dentro do contexto do eletromagnetismo, a opção de utilização de experimentos é consideravelmente

\footnotetext{
${ }^{+}$Theoretical framework in electromagnetism teaching: a literature review in Brazilian journals

* Recebido: 6 de março de 2020. Aceito: 24 de março de 2021.

${ }^{1}$ E-mail: daniel.truga@gmail.com; rodrigues.am@usp.br
} 
superior ao de recursos relacionados à tecnologia da informação e comunicação.

Palavras-chave: Eletromagnetismo; Ensino de Ciências; Ensino de Física; Revisão da Literatura.

\begin{abstract}
In this paper we present a literature review on the presence of theoretical references from the various fields of education and learning theories that guide the publications about the teaching of electromagnetism between 2000 and 2019. We chose to evaluate some of national journals in the area of science education or physics education. We selected A1 or A2 level journals in the areas of education or teaching assessment in the last four-year Qualis-Periodicals classification. The research resulted in a sample of 46 articles, which were organized in terms of their approaches, namely: use of experimentation, information and communication technologies and the presence of theoretical framework. Our analysis gave special attention to articles that presented theoretical framework based on the perspective of historical-cultural theory. As a result we found 4 articles that are explicitly oriented according to the historical-cultural theory in the context of electromagnetism teaching, discussing the motivating character that demonstrative and investigative activities can provide, making this reference an interesting choice for orientation and pedagogical planning in science teaching. Furthermore, we noted that within the context of electromagnetism, the option of using experiments is considerably superior to that of resources related to information and communication technology.
\end{abstract}

Keywords: Electromagnetism; Science Education; Physics Education; Literature Review.

\title{
I. Introdução
}

A pesquisa em ensino de física no Brasil, em relação aos seus conteúdos, está predominantemente centrada na área de mecânica clássica. A literatura mostra que os conteúdos da mecânica predominam nas pesquisas (MARTINS; GARCIA, 2011) talvez pela sua abundância de conceitos que regem nossa vida diária como massa, peso, velocidade, distância e a facilidade para realização de experimentos dentro e fora da sala de aula, além de 
atividades que envolvam o uso de simulações, animações e vídeos (ARAUJO; VEIT, 2004). Nesse sentido, Pieper e Andrade Neto (2015) comentam que o eletromagnetismo, em particular, é pouco pesquisado no Brasil, e falta destaque nas pesquisas acadêmicas.

Sabemos que no século XXI, principalmente em áreas urbanas e industrializadas, há uma imensa quantidade de aparelhos que funcionam graças à utilização da energia elétrica. A curiosidade dos alunos em entender como que aparelhos elétricos funcionam é explícita (SILVA, 2013). A atividade humana necessita, reproduz e se transforma com o uso de uma variedade de aparelhos eletrônicos como computadores, celulares, televisores, microondas, entre muitos outros. Os estudantes, nascidos e criados nessa era digital, acabam interagindo com diferentes materiais que envolvem ímãs e/ou eletricidade. Rocha (2001) manifesta que parte dos estudantes sente necessidade de relacionar a ciência que aprende nas escolas com o mundo natural e tecnológico que o rodeia.

Assim, como fruto da intelectualidade humana de desenvolver pensamento racional sobre os objetos ao nosso redor, concordamos com Gilbert, Boulter e Rutherford (1998) quando dizem que os alunos acabam por construir seus próprios modelos mentais de representação desses objetos e dos fenômenos que os governam. A compreensão de suas manifestações é importante para a inserção crítica no contexto tecnológico atual (PIEPER; ANDRADE NETO, 2015) ainda mais tendo a tecnologia como um dos assuntos que mais parecem despertar o interesse nos jovens (BARAM-TSABARI; YARDEN, 2005; CHRISTIDOU, 2006).

Por outro lado, os estudantes apresentam grande dificuldade no estudo sistemático dos sistemas elétricos e magnéticos, o que acaba acarretando em uma baixa apreciação teórica dos seus fenômenos (SILVA, 2012). Parte do problema do ensino de física encontra-se na banalização dos conceitos e na metodologia utilizada (BOSS; SOUZA FILHO; CALUZI, 2009) na qual muitas vezes é apenas uma leitura e transcrição do livro didático. Alguns autores defendem que a aprendizagem tende a ser mais significativa caso a física fosse abordada com mais ênfase em seus conceitos e menos em matematização (BRAGA; TEIXEIRA, 2006; PAZ, 2007).

É indiscutível a presença e a importância de aparelhos e fenômenos eletromagnéticos em nossas vidas. Outrossim, autores em diferentes pesquisas relatam a dificuldade de apreensão desses conceitos. A questão do ensino de eletromagnetismo poderia ser pensada para além das atividades didáticas realizadas dentro do contexto escolar e com o suporte de referenciais teóricos que possam contribuir para a elaboração de uma proposta de ensino significativo. Diferentemente da mecânica newtoniana, agora os alunos carecem de experiências empíricas que os auxiliem ao estudo dos fenômenos relacionados à estrutura da matéria, campos elétricos e magnéticos. São necessárias mediações entre o objeto manipulado pelos alunos em seus cotidianos e a efetiva interiorização dos pormenores que governam o rádio, a televisão, entre outros. Por isto, realizamos uma revisão da literatura a respeito dos 
diferentes referenciais teóricos que orientam pesquisadores e professores quando estes se debruçam sobre a elaboração de uma proposta didática de eletromagnetismo.

\section{Justificativa e fundamentação}

Neste trabalho, olhamos a fundamentação teórica de todos os artigos selecionados, com especial ênfase para aquelas relacionadas à teoria histórico-cultural de Vigotski "cuja maior contribuição pedagógica pode ser o resgate da função educacional do professor, a sua recolocação no centro do processo de ensino e aprendizagem" (GASPAR, 1997, p. 1). A teoria histórico-cultural na ótica da educação escolar tende a se opor à concepção tradicional de educação que não se preocupa muito com o desenvolvimento dos estudantes enquanto aprendizes, e acabam treinando e reforçando as funções mentais que estes já possuem, estabelecidas em crianças antes da idade escolar, como a percepção sensória, observação das aparências, pensamento empírico e memória (ENGENESS; LUND, 2018). Enxergamos que referenciais teóricos podem contribuir com a potencialidade do professor de buscar por concepções que o ajudem a refletir a própria prática docente e a relação conteúdo-ensinoaluno.

Ao longo dessa revisão, encontramos muitos trabalhos cujo foco da justificativa didático-metodológica é a importância da inserção de recursos diferenciados como atividades lúdicas propiciadas pelo uso da tecnologia ou atividades de experimentação ao invés do padrão giz e lousa das aulas tradicionais. No campo do uso de atividades experimentais, Monteiro et al. (2010, p. 372) comentam que é preciso, por parte dos professores, não apenas a apresentação de atividades de baixo custo ou de fácil construção, mas também "indicações de abordagem didática que explore amplamente todas as potencialidades do recurso à disposição". Resende e Fireman (2014) apontam que embora o uso de atividades experimentais seja uma abordagem a ser considerada para superação de uma educação engessada em modos tradicionais, a demonstração experimental não é, por si só, promotora de uma pedagogia crítica. De forma mais contundente, Gaspar (1997, p. 11) afirma que "só quem conhece a fundamentação teórica de uma experiência pode realizá-la de forma significativa e fazer com que ela possa promover a aquisição do conhecimento para a qual foi proposta e apresentada".

De modo semelhante Paula e Talim (2012), em uma revisão bibliográfica acerca do uso de ambientes virtuais e outros recursos midiáticos, apresentam dados suficientes para argumentarmos que há certo consenso a respeito da importância e os benefícios do uso de recursos tecnológicos em sala de aula por parte da comunidade científica. Ainda sobre essa revisão de Paula e Talim, Paula (2017) comenta que pesquisas científicas deveriam explicitar os fundamentos pedagógicos que sustentam o uso dos recursos midiáticos, em vez de revalidar a justificativa do uso dessas tecnologias em salas de aula. Além disso, a utilização de meios digitais implica em uma reestruturação da ação docente na qual o foco é o aluno e as diferentes formas de aprendizagem (SIQUEIRA; TORRES, 2010) descritas em diferentes 
referenciais teórico-metodológicos. A utilização de recursos tecnológicos em sala de aula sem uma concepção de como o aluno aprende pode ser erro metodológico (ARAUJO; VEIT, 2004). Assim, embora haja consenso sobre os aspectos positivos da inserção de recursos da tecnologia da informação e comunicação (TIC) no ensino de ciências, sua utilização deve ser especificamente planejada e estudada (OSBORNE; HENNESSY, 2003).

Neste contexto, notamos a importância de integrar objetivos, métodos e práticas de ensino de conhecimentos científicos em uma investigação elaborada e desenvolvida pelo professor para que todos os agentes, pesquisadores, professores e alunos sejam protagonistas no processo de aprendizagem (FREIESLEBEN; LODER; BECKER, 2017). Compreendemos sequência didática conforme explica Zabala $(2006,58)$ :

um conjunto de atividades ordenadas, estruturadas e articuladas para a realização de certos objetivos educacionais, que têm um principio e um fim conhecidos tanto pelos professores quanto pelos alunos.

A estruturação, articulação e análise dos dados provenientes dessas atividades poderiam ser feitos à luz de referenciais teóricos dos diversos campos da educação. Araujo e Veit (2004, p. 12) apontam que:

o desenvolvimento instrucional deve estar acoplado à pesquisa em ensino ou, pelo menos, levar em conta o conhecimento produzido pela pesquisa em ensino e os enfoques teóricos sobre aprendizagem compartilhados pela comunidade de educadores e pesquisadores em Ensino de Física.

Investigações anteriores também se propuseram a investigar a presença de referenciais teóricos em trabalhos relacionados ao ensino de ciências. Damasio e Peduzzi (2018, p. 6) ao analisarem 8 teses e 33 dissertações entre o período de 2005 e 2014 declaram: "no que se refere ao referencial educacional, 63\% não declararam seu embasamento. Em relação ao aporte epistemológico, 34\% também não se referiram à sua fundamentação". Greca, Costa e Moreira (2002, p. 63) investigaram 161 trabalhos do III Encontro Nacional de Pesquisa em Educação em Ciências e concluíram que em 52 trabalhos "não é apresentada uma fundamentação teórica que possa ser considerada como tal”.

Pontone Junior e Paula (2015, p. 4) investigaram artigos publicados nos principais periódicos de ensino de ciências e física entre 2009 e 2014 e constataram que "na maior parte dos artigos analisados, não encontramos menções explícitas ao referencial teórico adotado na pesquisa ou ao referencial teórico que orienta o uso desses recursos em sala de aula”. Pontone Junior e Paula (2015) estavam interessados em trabalhos que abordassem o uso, no ensino de ciências, de animações, simulações e laboratórios virtuais. Como resultado apresentam que "apenas 9 dentre as 32 pesquisas empíricas apresentaram reflexões acerca das bases teóricas para o ensino de ciências mediado por ambientes virtuais". 
Recentemente, Oliveira, Araújo e Veit (2017) em uma revisão sobre resolução de problemas em física, mostram que os conteúdos de magnetismo e eletromagnetismo são pouco discutidos quando comparados com outros conteúdos, como dinâmica e cinemática. Esse resultado corrobora os achados de outras revisões bibliográficas como as de Santos e Mackedanz (2019) sobre o ensino de física para crianças e Moreira et al. (2018) sobre o uso o uso de Arduino no ensino de física. Também indicando que o eletromagnetismo é um assunto negligenciado na pesquisa em ensino de Física quando comparado com outros conteúdos, Fávero e Sousa (2001, p. 146) já apontaram que: “os estudos de RP [resolução de problemas] em Física concentram-se, quase que exclusivamente, na Mecânica". Em última análise, essas revisões indicam a necessidade de desenvolver uma pesquisa focada no ensino de eletromagnetismo.

Uma vez que consideramos que a ação docente no ensino de ciências deve estar para além de uma mera transmissão de conhecimento, essa deveria contemplar uma aprendizagem que dialogue com as experiências e saberes dentro do contexto social e cultural dos estudantes. Cremos que dentro da esfera educacional, recursos e métodos utilizados para o planejamento de atividades didáticas poderiam ser estruturados a partir de concepções de ensino-aprendizagem com alguma fundamentação teórica do campo da psicologia da educação ou das teorias de ensino, por exemplo. Em outras palavras, para ganhos significativos na aprendizagem não basta apenas realizar atividades práticas, é preciso que os alunos realizem tarefas que estimulem a reflexão e o raciocínio com auxílio do professor (HAKE, 1998; QUINTAS; CARVALHO, 2016) e que estas tarefas estejam em contexto do ponto de vista do estudante (GASPAR, 1997). A partir de um referencial teórico a atividade didática ganha sentido e o professor pode compreender a interface entre a atividade de ensino concebida dentro do objetivo escolar e a importância de sua prática social como mediador do aprendizado.

\section{Perspectiva da teoria histórico-cultural para ensino de física}

Demos especial atenção à perspectiva teórica vigotskiana uma vez que ela busca parâmetros que possibilitam apreender os fenômenos no processo formativo, a partir da dimensão humana de formação dos indivíduos que, como seres socialmente determinados, estruturam suas atividades nas relações subjetivas e objetivas presentes nas ações humanas. Segundo Rigon, Asbahr e Moretti (2016, p. 25):

o projeto central da teoria histórico-cultural é estudar a formação da subjetividade dos indivíduos a partir de seu mundo objetivo, concreto, isto é, a formação da consciência humana em sua relação com a atividade.

Recentemente Bonfim, Solino e Gehlen (2019) ao analisarem a presença de pressupostos vigotskianos em resumos de dissertações e teses da área de Educação em 
Ciências entre 1972 e 2016, observaram que este referencial teórico aparece em 343 de 10.017 trabalhos.

Para nossa discussão, é importante entendermos que o estudante está imerso de modo ativo e criativo nas práticas sociais, culturais e históricas que sustentam as atividades humanas e a compreensão de que o desenvolvimento humano é fruto e percurso de um complexo processo dialético. $\mathrm{O}$ seio da teoria histórico-cultural rompeu com o entendimento da época relacionado ao desenvolvimento intelectual do sujeito. Vigotski, ao propor que "a determinação da consciência individual segue o esquema: atividade social coletiva - cultura signos - atividade individual - consciência individual" (DAVÝDOV, 1982, p. 164 apud ROSA; DAMAZIO, 2017, p. 154), marcou uma nova linha de investigação e pesquisa psicológica e pedagógica. Podemos entender em nosso contexto que a atividade social coletiva é a atividade de aprendizagem escolar. Dessa forma, cultura e signos fazem parte da linguagem mediadora própria do eletromagnetismo, como elétrons, gerador de energia elétrica, indução eletromagnética etc.

Compreendemos que há diferentes tipos de conceitos cada qual possuindo diferentes características e particularidades. Vigotski (2007) diferencia em conceitos científicos que são produzidos nas condições do ensino escolar, e propiciam a formação dos processos de generalização e abstração; e os conceitos cotidianos ou empíricos que são formados com base nas ações concretas da criança em seu cotidiano, fora do contexto da escola. Além disso, a tese vigotskiana indica que o desenvolvimento de funções psíquicas superiores é fruto de um fenômeno ativo de interiorização e apropriação do mundo exterior, mediado pela linguagem e pela cultura através de um processo dialético. Isto é, que o conhecimento ocorre primeiramente no mundo social, recheado e inundado de signos para então se transformar em conhecimento individual com ajuda de um parceiro mais capaz, como o professor. Gaspar (1997, p. 11) apresenta um exemplo a esse respeito:

não é possivel acreditar que [...] observando um bastão atritado com um lenço atrair papeizinhos alguém possa, sem conhecimento teórico prévio, concluir que o lenço cedeu ou tirou elétrons do bastão, este polarizou eletricamente os papeizinhos e assim os atraiu.

O reconhecimento da importância de partir das concepções prévias dos alunos também é descrito em outros referenciais teóricos como na teoria dos campos conceituais (VERGNAUD, 1990) e na teoria da aprendizagem significativa (AUSUBEL; NOVAK, 1980; MOREIRA, 1999). Muitos trabalhos em ensino de ciências que utilizam ideias vigotskianas, também utilizam outros referenciais teóricos de maneira conjunta (BONFIM; SOLINO; GEHLEN, 2019).

O modelo promovido por Vigotski faz referência à instrução e ao aprendizado como fontes do desenvolvimento psíquico, onde a instrução deveria preparar e motivar a criança para uma participação ativa e criadora nas práticas sociais existentes (LOMPSCHER, 1999). Contudo, o foco do processo de escolarização deveria ser que os estudantes possuam controle 
pleno e autêntico sobre o significado da informação que eles são capazes de reproduzir (DUARTE, 2016).

\section{Metodologia}

Para a realização deste trabalho, optamos por avaliar apenas alguns periódicos nacionais na área de ensino de ciência e ensino de física. A escolha dos periódicos que avaliaríamos foi feita da seguinte maneira: selecionamos os periódicos níveis A1 ou A2 nas áreas de avaliação de educação ou ensino na última classificação quadrienal, de 2013 a 2016, disponível na plataforma online Sucupira, Qualis-Periódicos ${ }^{2}$. O total de periódicos encontrados foi: 121 para Educação-A1, 380 para Educação-A2, 145 para Ensino-A1 e 198 para Ensino-A2. Ressalta-se que alguns periódicos podem aparecer em mais de uma categoria analisada.

A partir disso, delimitamos a busca apenas nos periódicos que contivessem em seu nome pelo menos uma das palavras "física" ou "ciência". Além disso, foram selecionados apenas aqueles que apresentassem em seu escopo o ensino de ciências naturais. Por exemplo, o periódico Histórias, Ciências, Saúde e a Revista Brasileira de Ciências Sociais, embora tenham passado em todos os crivos - foi avaliado nível A1 ou A2 na área de ensino ou educação, e possui a palavra-chave "ciência" em seu título - não foi selecionado visto que seu escopo de publicação não abrange pesquisas relacionados ao ensino de ciências físicas. Por último, consideramos apenas os periódicos que possuíssem em seus respectivos endereços eletrônicos a opção de busca nas categorias autor, título, resumo, termos indexados e texto completo.

Consideramos a opção de busca em texto completo dentro do periódico como de suma importância para termos melhor noção do conteúdo das publicações. Alguns periódicos como Ciência e Educação, Ensaio Pesquisa em Educação em Ciências e Revista Brasileira de Ensino de Física não foram considerados visto que em seus respectivos endereços eletrônicos não é possível pesquisar pelos termos escolhidos no texto completo. Ressaltamos que esses são importantes periódicos para a área de Ensino de Física. Contudo, ao reconhecer que a busca em seus respectivos endereços eletrônicos é limitada por autor, título, resumo e termos indexados, a introdução desses periódicos traria uma inconsistência metodológica. Além disso, ao optarmos por periódicos que permitem a busca em texto completo, não precisamos nos preocupar em exaurir os termos-chaves na busca de artigos. Afinal, parece muito improvável que haja algum artigo relevante para análise que, em nenhum momento ao longo do texto, tenha utilizado pelo menos um dos termos: eletromagnetismo, magnetismo,

\footnotetext{
2 A plataforma online pode ser acessada diretamente pelo endereço eletrônico $<$ https://sucupira.capes.gov.br/sucupira/>. O item Qualis-Periódicos "disponibiliza uma lista com a classificação dos veículos utilizados pelos programas de pós-graduação para a divulgação da sua produção", informação retirada do próprio endereço eletrônico em dezembro de 2019.
} 
eletricidade, elétrico, elétrica. Utilizamos esses cinco termos para realizar a busca pelos artigos.

Finalmente, os periódicos analisados foram os seguintes: Caderno Brasileiro de Ensino de Física (CBEF); Investigações em Ensino de Ciências (IENCI); Revista Brasileira de Ensino de Ciência e Tecnologia (RBECT); Revista de Ensino de Ciências e Matemática (REnCiMa); Revista Brasileira de Pesquisa em Educação em Ciências (RBPEC); Acta Scientiae: Revista de Ensino de Ciências e Matemática (RECM); Amazônia - Revista de Educação em Ciências e Matemáticas (ARECM) e Revista de Educação, Ciências e Matemática (RECMAT). Delimitamos as publicações a partir do ano 2000. Isto é, analisamos os trabalhos publicados entre os anos 2000 e 2019.

A pesquisa se concentrou em publicações direcionadas ao ensino de física dentro do ambiente da educação básica e universitária. Assim, artigos gerais nos quais o direcionamento fosse a formação de professores, levantamento de concepções espontâneas dos alunos e suas motivações, análises amplas de currículo, cálculos teóricos para construções de arranjos experimentais ou estudos históricos da física foram desconsiderados. Por exemplo, trabalhos como o Scarinci e Pacca (2010) sobre análise e investigação de professores de física em programas de formação contínua, Silveira e Marques (2012) sobre apresentação de dois projetos de motores elétricos de indução, e Pereira e Silva (2017) a respeito de uma análise histórica de significados físicos para o conceito de potencial vetor foram excluídos. Como observado por Pereira e Ostermann (2009) e Batista e Peduzzi (2019) a exclusão de artigos não implica que estes não são valiosos para a pesquisa em ensino de física, mas apenas que não compõe o escopo deste trabalho de revisão.

Outrossim, pontuamos que o intuito desta revisão bibliográfica não é exaurir as possibilidades da abordagem do ensino de eletromagnetismo. Essa tarefa circunda e oferece um direcionamento ao tentarmos compreender os principais referenciais teóricos que sustentam as estratégias adotadas por professores e pesquisadores dentro e fora da sala de aula ao redor de propostas pedagógicas sobre este tema. Em particular, analisar a presença da teoria histórico-cultural como referencial teórico para elaboração e aplicação de atividades didáticas referente aos tópicos complexos da eletricidade e do magnetismo. Para isso, baseamos nossa análise segundo os moldes da análise apresentada por Batista e Peduzzi (2019).

\section{Resultados e análise}

$\mathrm{Na}$ tabela 1 estão distribuídos os quarenta e seis (46) trabalhos selecionados. Nas colunas encontram-se: o ano de publicação e o número de artigos por periódico. As células preenchidas de preto indicam que o periódico em questão não existia naquele(s) ano(s). Nesta distribuição, os dados permitem constatar que o ensino de eletromagnetismo é majoritariamente representado no $\operatorname{CBEF}$ (23). A representação diversificada e uma média de 2 artigos por ano em alguns dos principais periódicos reflete que a comunidade científica do 
ensino de física reconhece a importância da investigação acerca da temática do eletromagnetismo. Em alguns periódicos, contudo, essa temática apresenta pouca visibilidade.

Tabela 1 - Apresenta a distribuição das publicações descritas na metodologia ao longo das últimas 2 décadas.

\begin{tabular}{|c|c|c|c|c|c|c|c|c|}
\hline \multirow[t]{2}{*}{$\begin{array}{c}\text { Ano } \\
(\mathbf{2 0 x x})\end{array}$} & \multicolumn{8}{|c|}{ Número de artigos por revista } \\
\hline & CBEF & IENCI & RBECT & REnCiMa & RBPEC & RECM & $\overline{\mathrm{ARECM}}$ & RECMAT \\
\hline 00 & & & & & & & & \\
\hline 01 & 1 & 1 & & & & & & \\
\hline 02 & 1 & 1 & & & & & & \\
\hline 03 & 2 & & & & & & & \\
\hline 04 & 1 & & & & & & & \\
\hline 05 & & & & & & & & \\
\hline 06 & 1 & & & & & & & \\
\hline 07 & & & & & & & & \\
\hline 08 & 1 & & & & & 1 & & \\
\hline 09 & 2 & & & & & & & \\
\hline 10 & 2 & & & & & & & \\
\hline 11 & 2 & & & & 2 & & & \\
\hline 12 & 4 & & & 2 & & & & \\
\hline 13 & & & 1 & & & 1 & & \\
\hline 14 & & 1 & 1 & 1 & & & & \\
\hline 15 & 2 & & & & & 1 & & \\
\hline 16 & 1 & & & & 1 & & & \\
\hline 17 & 2 & 1 & & 1 & 1 & & 1 & \\
\hline 18 & 1 & & & 1 & & & & \\
\hline 19 & & & 2 & & 1 & & & 1 \\
\hline
\end{tabular}

Na tabela 2 caracterizamos os artigos avaliados conforme a escolaridade alvo dos autores ou o nível de ensino no qual a intervenção didática foi realizada. Alguns artigos foram classificados em mais de um nível de ensino simultaneamente, isso ocorreu quando os autores apontaram que o trabalho por eles apresentado pode ser realizado em mais de um nível de escolaridade.

Tabela 2 - Organiza os artigos segundo o nível de ensino recomendado pelos autores.

\begin{tabular}{cc}
\hline Nível de Ensino & $\begin{array}{c}\text { Número de } \\
\text { artigos }\end{array}$ \\
\hline Fundamental I & 4 \\
Fundamental II & 5 \\
Educação de Jovens e Adultos & 1 \\
Ensino Médio & 24 \\
Ensino Médio com Técnico & 8 \\
\hline Ensino Superior & 5 \\
\hline
\end{tabular}


Notamos que a maior concentração de trabalhos com o assunto de eletromagnetismo possui o foco no ensino médio. Esse resultado é razoável ao levarmos em consideração que o conteúdo referente ao eletromagnetismo é majoritariamente presente nos livros didáticos do ensino médio quando comparado ao ensino fundamental. Por outro lado, o baixo número de artigos direcionados para o ensino superior chama atenção visto que as disciplinas que envolvem o eletromagnetismo são reconhecidamente difíceis e talvez fosse um campo de estudo indicado para desenvolver pesquisas mais aprofundadas na área de ensino. Esse é um ponto interessante que demanda pesquisas posteriores.

Notamos que, em geral, os trabalhos direcionados ao ensino fundamental possuem o foco da atividade em uma interação investigativa através de experimentos realizados em sala de aula, tais como descritos por Lopes, Stein-Barana e Moreno (2009); Teixeira, Muramatsu e Alves (2017); Azevedo e Fireman (2017); Matos e Valadares (2001); Silva Junior et al. (2019). Esse resultado está de acordo com a revisão realizada por Santos e Mackedanz (2019, p. 225) que investigaram o ensino de física para crianças, apontando a predominância de experimentos como recurso didático. Neste contexto, os professores "buscaram metodologias inovadoras e diversificadas, a partir das quais os alunos puderam desenvolver sua participação ativa, sua autonomia, a interação com o conceito físico abordado e os demais sujeitos".

O único trabalho destinado à EJA (GONZALES; ROSA, 2014) optou pelo uso de ambientes virtuais de ensino, no qual os autores fizeram uso de simulações para trabalhar com circuitos elétricos e utilizaram da teoria da aprendizagem significativa para elaboração da sequência didática.

A tabela 3 organiza os 46 trabalhos avaliados em relação à utilização de recursos TIC e/ou experimentação considerando a adoção de algum referencial teórico.

Tabela 3 - Cruzamento dos dados a respeito da utilização de experimentos e recursos TIC com a presença de referencial teórico.

\begin{tabular}{cccc}
\hline \multicolumn{4}{c}{ Foi orientado por algum referencial teórico? } \\
\hline & Não & Sim & Total \\
\hline $\begin{array}{c}\text { Sem } \\
\text { experimentos } \\
\text { ou TIC }\end{array}$ & 2 & 4 & 6 \\
$\begin{array}{c}\text { Com } \\
\text { experimentos e } \\
\text { TIC }\end{array}$ & 0 & 5 & 5 \\
$\begin{array}{c}\text { Apenas } \\
\text { experimentos } \\
\text { Apenas TIC }\end{array}$ & 10 & 14 & 24 \\
\hline Total & 2 & 9 & 11 \\
\hline
\end{tabular}

Da tabela 3, nota-se que apenas seis artigos não utilizam TIC ou experimentos. Por exemplo, Oliveira, Reis e Silva (2018) observaram como os trabalhos de Faraday poderiam 
contribuir para o estudo da natureza elétrica da matéria a partir da abordagem contextual e da contextualização histórica. Por outro lado, cinco trabalhos relataram o uso de ambos os recursos. Em particular, Quintas e Carvalho (2016) mostraram como a união de atividades práticas de laboratório e recursos educativos digitais podem afetar positivamente a aprendizagem de eletricidade em estudantes de escolas portuguesas. Em geral, a utilização dos recursos é excludente em sua maioria, isto é, ou opta-se pela experimentação ou pelo uso de TIC. Professores e pesquisadores optaram duas vezes mais pela utilização da experimentação (24) em relação à TIC (11).

Avançando na discussão, na tabela 4 cruzamos os dados referentes à utilização de algum referencial teórico com a descrição de uma intervenção didática.

Tabela 4 - Relação dos trabalhos que apresentam intervenção didática com a explícita menção ao referencial teórico utilizado.

\begin{tabular}{cccc}
\hline & O artigo relata uma intervenção didática? & \\
\hline $\begin{array}{c}\text { Foi orientado por } \\
\text { algum referencial } \\
\text { teórico? }\end{array}$ & Não & Sim & Total \\
Sim & 2 & 30 & 32 \\
Não & 11 & 3 & 14 \\
\hline Total & 13 & 33 & 46 \\
\hline
\end{tabular}

Interessante notar a grande presença de referenciais que embasaram as intervenções didáticas, independentemente do instrumento metodológico utilizado. Apresentado na tabela 4, dos 33 trabalhos que descrevem uma intervenção didática para o ensino de eletromagnetismo, 30 descrevem os referenciais teóricos adotados. Encontramos a relação entre o uso de um referencial teórico para elaboração e aplicação de uma intervenção didática como sendo significativa ${ }^{3}$. Organizamos na tabela 5 , em linhas gerais, os 32 artigos orientados por referenciais teóricos.

Tabela 5 - Relação dos referenciais teóricos utilizados para o ensino de eletromagnetismo.

\begin{tabular}{cc}
\hline Referencial teórico & Artigo \\
\hline História e filosofia da ciência & Guerra, Reis e Braga (2004); Oliveira, Reis e \\
Construtivismo na atividade de & Silva (2018) \\
laboratório aliada à história da ciência & Pinto, Silva e Ferreira (2017) \\
Just-in-Time Teaching aliado ao Peer & Müller et al. (2012); Oliveira, Veit e Araujo
\end{tabular}

\footnotetext{
${ }^{3}$ Realizamos o teste do qui-quadrado e obtivemos significância $\mathrm{p}<0,001$. Em termos simplificados, isso permite concluir que a associação entre as duas variáveis (intervenção didática e presença de fundamentação teórica) não é fruto de acaso.
} 


$\begin{array}{cc}\text { Instruction } & \text { (2015); Quintas e Carvalho (2016) } \\ \text { Team-Based Learning } & \text { Espinosa, Araujo e Veit (2019) } \\ \text { Três momentos pedagógicos } & \begin{array}{c}\text { Macêdo, Dickman e Andrade (2012); Pires, } \\ \text { Ferrari e Queiroz (2013) }\end{array} \\ \text { Linguagens geradores de viabilidade } & \text { Camargo e Nardi (2008) } \\ \text { comunicacional } & \text { Sousa e Fávero (2002); Sousa, Moreira e Matheus } \\ \text { Teoria dos campos conceituais } & \text { (2011); Leitão, Fernandes e Lage (2018); Rocha e } \\ \text { Teoria da mediação cognitiva } & \text { Catarino (2019) } \\ \text { Estatutos do conhecimento biológico e Andrade Neto (2015) } & \text { Moraes, Oliveira e Goldschimdt (2017) } \\ \text { Epistemologia genética de Jean Piaget } & \text { Freiesleben, Loder e Becker (2017) } \\ \text { Teoria histórico-cultural } & \text { Erthal e Gaspar (2006); Monteiro et al. (2010); } \\ \text { Paula e Talim (2012); Setlik e Higa (2019) }\end{array}$

A teoria da aprendizagem significativa de David Ausubel foi a mais presente dentre os referenciais teóricos escolhidos pelos autores, sendo o alicerce de pelo menos 6 diferentes propostas didáticas. A predominância da teoria da aprendizagem significativa em artigos referentes ao ensino de física e TIC também é relatada por Martins e Garcia (2011). Por outro lado, não encontramos propostas didáticas para o ensino de eletromagnetismo explicitamente pautados em ideais freireanos, por exemplo.

\section{Discussão dos artigos selecionados}

Avançando na discussão, na tabela 6 e 7 apresentamos os trabalhos selecionados para análise descritiva e seus objetivos. Pela leitura dos títulos dos artigos vemos que três dos quatro trabalhos optam pelo estudo da eletrodinâmica mediado por atividades experimentais. 
Tabela 6 - Autoria e título dos artigos analisados.

\begin{tabular}{|c|c|}
\hline Autorias & Títulos \\
\hline $\begin{array}{l}\text { Erthal e Gaspar } \\
\qquad(2006)\end{array}$ & $\begin{array}{c}\text { "Atividades experimentais de demonstração para o ensino da corrente } \\
\text { alternada ao nível do ensino médio" }\end{array}$ \\
\hline $\begin{array}{l}\text { Monteiro et al. } \\
\qquad(2010)\end{array}$ & $\begin{array}{l}\text { "As atividades de demonstração e a teoria de Vigotski: um motor } \\
\text { elétrico de fácil construção e de baixo custo" }\end{array}$ \\
\hline $\begin{array}{l}\text { Paula e Talim } \\
\qquad(2012)\end{array}$ & $\begin{array}{l}\text { "Uso coordenado de ambientes virtuais e outros recursos mediacionais } \\
\text { no ensino de circuitos elétricos" }\end{array}$ \\
\hline $\begin{array}{l}\text { Setlik e Higa } \\
\qquad(2019)\end{array}$ & $\begin{array}{c}\text { "Contribuições e Dificuldades de Práticas de Leitura e Escrita para } \\
\text { Ensinar e Aprender Física no Ensino Médio: Reflexões à Luz da Cultura } \\
\text { Escolar" }\end{array}$ \\
\hline
\end{tabular}

No tabela 7, encontram-se as autorias e excertos de textos que identificam os objetivos de cada artigo.

Tabela 7 - Autoria e objetivos dos artigos analisados.

\begin{tabular}{|c|c|}
\hline Autorias & Objetivo dos artigos \\
\hline $\begin{array}{l}\text { Erthal e } \\
\text { Gaspar } \\
(2006)\end{array}$ & $\begin{array}{c}\text { "[apresentar] o conceito de corrente alternada centrado em atividades } \\
\text { experimentais de demonstração". (p. 347) }\end{array}$ \\
\hline $\begin{array}{l}\text { Monteiro et } \\
\text { al. (2010) }\end{array}$ & $\begin{array}{c}\text { "[apresentar] uma proposta de atividade experimental de demonstração de } \\
\text { fácil montagem e de baixo custo, cuja abordagem didático-pedagógica segue } \\
\text { as indicações da teoria sócio-histórica de Vigotski." (p. 374). }\end{array}$ \\
\hline $\begin{array}{c}\text { Paula e } \\
\text { Talim (2012) }\end{array}$ & $\begin{array}{l}\text { “investigar a percepção dos estudantes acerca do uso coordenado de um } \\
\text { Laboratório Virtual com outros recursos mediacionais”. (p. 636) Além disso, } \\
\text { os autores também discutem duas questões teóricas “(i) quais são os } \\
\text { fundamentos teórico-metodológicos que sustentam as escolhas pedagógicas } \\
\text { realizadas durante a concepção e a articulação dos recursos mediacionais } \\
\text { utilizados em nosso curso? (ii) que expectativas sobre as contribuições do LV } \\
\text { estão contidas nesses fundamentos?”. (p. 619). }\end{array}$ \\
\hline $\begin{array}{l}\text { Setlik e Higa } \\
\quad \text { (2019) }\end{array}$ & $\begin{array}{l}\text { "O objetivo desta investigação é analisar as perspectivas de diferentes } \\
\text { sujeitos - professor de Física e estudantes do Ensino Médio - de um contexto } \\
\text { escolar sobre as contribuições e dificuldades de práticas de leitura e escrita } \\
\text { em aulas de Física, tecendo reflexões à luz dos conceitos de cultura escolar e } \\
\text { da escola”. (p. 455). }\end{array}$ \\
\hline
\end{tabular}


Destaca-se nos objetivos dos trabalhos que o aporte fornecido pela teoria históricocultural, mais especificamente o conceito de ação mediada entre o aluno e o sujeito mais capaz, personificado na imagem do professor, possibilita a investigação de diferentes conceitos a partir de diferentes práticas metodológicas: uso de experimentação (ERTHAL; GASPAR, 2006; MONTEIRO et al., 2010) ou uma combinação de recursos como realização de experimentos e laboratório virtual simulador de circuitos (PAULA; TALIM, 2012). Há também a possibilidade da caracterização das práticas de leitura e escrita de textos nas aulas de Física para compreender o processo de ensino e aprendizagem (SETLIK; HIGA, 2019). Os quatro trabalhos tiveram como objeto de investigação alunos do ensino médio.

Em Monteiro et al. (2010, p. 378) não são apresentados dados de uma intervenção didática, ou seja, o referencial teórico foi suporte para criar algumas questões nas quais pudessem "nortear e facilitar o trabalho do professor em promover interações sociais". Ademais, os autores pontuam que as perguntas encaminhadoras de discussão e da atividade como "qual a contribuição do ímã para o movimento do motor?" também servem para contribuir que a atividade ofereça maior potencial de exploração, isso pois, "para cada exploração possível, existe a possibilidade de interações sociais desencadeadas pela contextualização do fenômeno discutido". Nesse trabalho os autores descrevem a montagem experimental de uma mini ventoinha em diversos passos ilustrados com figuras, seguidas da explicação física. Também, apontam para a importância da mediação do professor na interação social da sala de aula durante o estudo da interação entre a corrente elétrica e o campo magnético. Os autores utilizam do suporte teórico da teoria histórico-cultural um direcionamento para exploração das potencialidades do experimento. Foco na proposição de James Wertsch ao longo das atividades de demonstração: a possibilidade de ocorrer a mediação semiótica aumenta à medida que a atividade oferecer maior potencial de exploração.

Erthal e Gaspar (2006, p. 347) para começarem a elaboração da intervenção didática, aplicaram um questionário com seis questões de múltipla escolha a respeito das concepções iniciais dos alunos. O questionário teve dois objetivos: "avaliar o conhecimento dos alunos sobre a corrente alternada" e "obter elementos que orientassem a preparação do material instrucional para a sua apresentação em sala de aula, ao nível do ensino médio". Como resultado, encontraram que apenas 19\% dos 132 alunos "mostraram saber que existem dois tipos de corrente elétrica e que a corrente elétrica que chega às suas casas é alternada" (op. cit., p. 348). Em posse do resultado do questionário, os autores selecionaram 4 diferentes conteúdos (conceito ou tecnologia) e 4 respectivas demonstrações. As relações conteúdodemonstração escolhidas pelos autores foram: (i) motor de corrente alternada (campo girante) - polia de arrasto magnético (ii) indução eletromagnética: leis de Faraday e Lenz - variação do campo magnético no interior de uma bobina (iii) geração de energia elétrica - gerador eletromagnético (iv) motor de corrente alternada (ressonância) - motor síncrono. Utilizam-se da teoria histórico-cultural para direcionar o olhar para as interações sociais conduzidas pelo 
parceiro mais capaz e mediador materializadas no professor. Observam a apropriação do conhecimento físico por parte dos alunos a partir das relações que estes eram capazes de realizar com os outros sujeitos e com o mundo cotidiano.

De maneira semelhante ao trabalho de Monteiro et al. (2010), Erthal e Gaspar (2006, p. 352) destacam que sempre buscaram pela interação social durante a apresentação das demonstrações, que de acordo com a teoria histórico-cultural "é o veículo fundamental para a transmissão dinâmica do conhecimento social, histórico e culturalmente desenvolvido". O caráter nem sempre intuitivo dos fenômenos eletromagnéticos propicia excelentes momentos de provocação por parte do professor e também por parte dos estudantes. Durante a última demonstração - do motor síncrono - os alunos foram também capazes de fazer analogias relacionadas aos seus cotidianos com os conceitos de frequência, fase e corrente alternada. Uma semana após a intervenção didática, os alunos responderam a um novo questionário, desta vez com três questões discursivas a respeito da temática de geração de eletricidade e corrente elétrica. Analisando as respostas em três diferentes graus (certas, parcialmente certas, erradas), os autores percebem que houve uma evolução conceitual satisfatória em relação ao que os alunos conheciam sobre corrente alternada: "obtivemos um bom nível de acertos na primeira e segunda questão, o que se acentua pelo fato das respostas serem dissertativas" (op. cit., p. 354).

Paula e Talim (2012) apoiados na concepção de ação mediada de Wertsch (1998) percebem a importância da utilização de um Laboratório Virtual Simulador de Circuitos (LV) em conjunto ao Laboratório Real (LR) uma vez que cada recurso possui especificidades próprias e ações mediadas características. Além do LV de circuitos elétricos e os experimentos realizados no LR, os autores descrevem seis outros recursos mediacionais que utilizaram sistematicamente, a saber: um caderno dedicado à produção de relatórios dos experimentos realizados no laboratório real; uma série de demonstrações, investigações compartilhadas e atividades em grupo realizadas em sala de aula; aulas expositivas dedicadas à apresentação de conceitos, modelos e teorias, bem como às discussões das atividades feitas em sala de aula ou no laboratório; um livro didático de física para o ensino médio; diversas listas de exercícios e um caderno dedicado à produção de registros das atividades feitas em casa ou em sala de aula.

Diferentemente da estratégia adotada por Erthal e Gaspar (2006) que aplicaram anteriormente à intervenção didática um questionário para sondagem do conhecimento prévio dos alunos, Paula e Talim (2012, p. 614) aplicaram um questionário a posteriori com o intuito de elaborarem "uma interpretação teórica das escolhas que nos levaram a conceber e a coordenar os recursos que utilizamos". Ou seja, após o trimestre letivo no qual atuaram em sala de aula, os autores aplicaram um questionário a todos os estudantes que compunham as sete turmas. O objetivo era "ter uma ideia acerca do engajamento desses sujeitos com o curso e com os recursos mediacionais nele utilizados" (op. cit., p. 637). O curso ao qual se referem é o curso de física do primeiro ano básico comum de uma escola pública federal dedicada à 
formação técnica de nível médio. O questionário foi dividido em duas partes. A primeira destinava-se a avaliar o comportamento e atitudes dos estudantes ao longo do trimestre; na segunda parte os alunos avaliavam os recursos e as estratégias usados na sala de aula ou no laboratório.

Ao considerarem o engajamento dos alunos nas ações mediadas pelos recursos mediacionais, os autores concluíram que "na visão dos alunos, com exceção, novamente, do livro didático, o LV contribuiu fortemente para todas as outras ações mediadas de ensino e aprendizagem e seus respectivos recursos mediacionais" (op. cit., p. 641). Esse dado deve ser interpretado da seguinte forma: o uso do LV facilitou, para grande maioria dos estudantes, a realização dos experimentos de laboratório, compreensão de demonstrações e experimentos feitos em sala, produção de bons relatórios das atividades práticas, entre outros.

A utilização de diversos recursos mediacionais apresentados por Paula e Talim (2012) talvez não apresentassem resultados promissores na direção de engajamento e aprendizagem dos alunos se não houvesse destaque para o papel mediador do professor, conceito central dentro da perspectiva histórico-cultural.

Diferentemente dos três trabalhos anteriores nos quais foram relatadas a construção e utilização de atividades experimentais para o ensino de eletrodinâmica, Setlik e Higa (2019) se apropriam dos pressupostos de Vigotski e Bakhtin sobre aprendizagem e linguagem. As autoras destacam que, operando dentro da zona de desenvolvimento proximal vigotskiana, a leitura e escrita em aulas de física podem potencializar atividades permitindo que o estudante "se torne mais consciente de seus conceitos espontâneos pela descrição verbal, ao mesmo tempo em que aproxima os conceitos científicos da sua vivência cotidiana, atribuindo sentidos no nível mais concreto" (op. cit., p. 454).

A partir de Bakhtin, as autoras discutem a importância da escrita contextualizada dos conceitos por parte dos alunos, dividindo o foco com a escrita apenas formal dos conceitos. Em outras palavras, é importante que, ao almejar a aprendizagem, professores busquem "situações que enfatizem a expressão do estudante com relação à sua subjetividade e cotidiano buscando aproximar conceitos espontâneos e não espontâneos também pela expressão verbal" (p. 454). Nesse sentido, Setlik e Higa (2019) analisam, a partir de entrevistas, as diferentes vozes de professores e alunos sobre a contribuição e potencialidades da leitura e escrita nas aulas que envolveram tópicos de eletromagnetismo. Para isso, utilizaram principalmente textos contidos no próprio livro didático de física utilizado pela escola, que remetiam aos experimentos desenvolvidos por Ampère, Oersted e Faraday; e a escrita de uma carta a William Gilbert, que no final do século XVI incorporou a enorme quantidade de observações a respeito de ímãs e efeitos magnéticos.

As autoras sugerem que a proposta de leitura dos dois textos e a forma como o aluno interagiu com os diversos enunciados (atividades, experimentos, vídeos, esquemas, discussões, entre outros) também podem ter influenciado nos sentidos que ele construiu para a leitura sobre a temática. Além disso, apontam que trabalhar atividades que envolvam leitura e 
escrita não é exclusivo do professor de língua portuguesa. Por fim, concluem que ao longo das atividades desenvolvidas "foi possível desenvolver novas formas de trabalhar o ler e o escrever que permitiram outras possibilidades para refletir e construir conhecimentos em Física" (op. cit., p.477). As autoras, apoiadas em Vigotski, consideram o papel da aprendizagem como estímulo ao desenvolvimento e a contextualização dos conceitos científicos para além dos significados das palavras. De Bakthin, ampliam o significado das palavras, analisando a linguagem em seus acontecimentos e relações sociais.

\section{Considerações finais}

Resgatando o objetivo deste trabalho - apresentar um levantamento bibliográfico acerca da presença de referenciais teóricos em artigos sobre o ensino de eletromagnetismo presente em alguns dos principais periódicos do ensino de ciências e ensino de física constatamos que os resultados encontrados podem evidenciar dois pontos: (1) é amplamente discutido pela literatura e há certo consenso no entendimento que apenas a utilização de atividades experimentais ou de recursos relacionados à TIC pouco contribuem para o aprendizado significativo dos alunos, tanto dentro do contexto de suas ações independentes em relação ao fenômeno físico quanto o estabelecimento de conexões entre o objeto estudado com a vida do cotidiano; (2) uma possível superação para esse cenário é a realização, por parte do professor, de investigações, atividades e ambientes interacionistas nos quais permitam uma troca dialógica entre o parceiro mais capaz e o aprendiz. Há diversos referenciais teóricos e recursos metodológicos que podem dar suporte à criação das mais diversas atividades de ensino, nessa revisão encontramos pelo menos 14 referenciais teóricos diferentes que deram suporte a 30 diferentes intervenções.

Em particular, analisamos os artigos que utilizaram da perspectiva histórico-cultural como alicerce de uma intervenção didática ou de elaboração de uma possível sequência didática. Nesse contexto, percebemos que independentemente do conteúdo trabalhado, os autores direcionam atenção às relações mediacionais que devem ser estimuladas dentro da sala de aula, sendo estas dos mais diversos tipos como professor-aluno, aluno-aluno, alunoexperimento, aluno-simulações, entre outras. Contudo, conforme nos alerta Vigotski (2002), a interação social ou mediação pedagógica promovida pelo professor deve ocorrer dentro da zona de desenvolvimento proximal do educando, a fim de viabilizar condições para que os aprendizes se apropriem do conhecimento científico. Em nossa análise constatamos que a mediação e a interação entre os recursos mediacionais foram os conceitos vigotskianos mais utilizados. Esse resultado está em consonância com os resultados apresentados por Bonfim, Solino e Gehlen (2019, p. 242) que relatam: "os conceitos vygotskyanos mais utilizados pelos pesquisadores da área são a Interação (37\%), Mediação (23\%) e Zona de Desenvolvimento Proximal (8\%), tendo como base o total de 343 resumos dos trabalhos analisados".

$\mathrm{Na}$ perspectiva da teoria histórico-cultural discute-se o caráter motivador que atividades demonstrativas e investigativas podem propiciar, fazendo desse referencial uma 
interessante escolha para orientação e planejamento pedagógico no ensino de ciências. Monteiro e Gaspar (2007) comentam que do ponto de vista vigotskiano, a interiorização de conceitos científicos pelos alunos sucede o conhecimento histórica e culturalmente acumulado, o que resulta na necessidade da interação entre o professor - papel do parceiro mais capaz e agente mediador do conhecimento acumulado - com os estudantes.

Dos 46 artigos avaliados, notamos que a descrição de um referencial teórico é apresentada, em maior ou menor grau, em 32 artigos, sendo que 30 deste montante também descrevem uma intervenção didática. Apenas 6 artigos não descreveram, ao mesmo tempo, o uso de um recurso mediacional (experimento ou TIC). Poucos trabalhos (5) descrevem a utilização de experimentos e de TIC para mesma intervenção didática. Também notamos que dentro do contexto do ensino de eletromagnetismo, a opção de utilização de experimentos é superior ao de recursos mediacionais: 29 artigos utilizam alguma forma de experimentação, enquanto apenas 16 trabalham com algum recurso TIC (animação, simulação, filmes dentre outros). Uma menor utilização de recursos TIC em comparação à realização de experimentos pode ser compreendida se levarmos em consideração que não faz parte da realidade do contexto escolar brasileiro a presença e disponibilidade de computadores, tablets ou internet que possam dar suporte à elaboração de atividades nesse formato (ALBINO; SOUZA, 2016).

\section{Agradecimentos}

O presente trabalho foi realizado com apoio da Coordenação de Aperfeiçoamento de Pessoal de Nível Superior - Brasil (CAPES) - Código de Financiamento 001 e do Programa de Pós-Graduação Interunidades em Ensino de Ciências da Universidade de São Paulo.

\section{Referências bibliográficas}

ALBINO, R.; SOUZA, C. A. Avaliação do nível de uso das TICs em escolas brasileiras: uma exploração dos dados da pesquisa “TIC educação". Revista Economia e Gestão, v. 16, n. 43, p. 101-125, 2016.

ARAUJO, I. S.; VEIT, E. A. Uma revisão da literatura sobre estudos relativos a tecnologias computacionais no ensino de Física. Revista Brasileira de Pesquisa em Educação em Ciências, v. 4, n. 3, p. 5-18, 2004.

AUSUBEL, D. P.; NOVAK, J. D. Psicologia Educacional. Rio de Janeiro: Interamericana. 1980.

AZEVEDO, L. B.; FIREMAN, E. C. Sequência de ensino investigativa: problematizando aulas de ciências nos anos iniciais com conteúdos de eletricidade. Revista de Ensino de Ciências e Matemática, v. 8, n. 2, p. 143-161, 2017. 
AZEVEDO, R. L. Uso de organizadores prévios na aprendizagem significativa do eletromagnetismo. Acta Scientiae, v. 15, n. 2, p. 304-320, 2013.

BARAM TSABARI, A.; E YARDEN, A. Characterizing children's spontaneous interests in science and technology. International Journal of Science Education, v. 27, n. 7, p. 803826, 2005.

BATISTA, C. A. S.; PEDUZZI, L. O. Q. Concepções epistemológicas de Larry Laudan: uma ampla revisão bibliográfica nos principais periódicos brasileiros do ensino de ciências e ensino de física. Investigações em Ensino de Ciências, v. 24, n. 2, p. 38-55, 2019.

BONFIM, V.; SOLINO, A. P.; GEHLEN, S. T. Vygotsky na pesquisa em educação em ciências no Brasil: um panorama histórico. Revista Electrónica de Enseñanza de las Ciencias, v. 18, n. 1, p. 224-250, 2019.

BOSS, S. L. B.; SOUZA FILHO, M. P.; CALUZI, J. J. Fontes primárias e aprendizagem significativa: aquisição de subsunçores para a aprendizagem do conceito de carta elétrica. In: ENCONTRO NACIONAL DE PESQUISA EM EDUCAÇÃO EM CIÊNCIAS, 7, 2009, Santa Catarina. Atas [...] Florianópolis, 2009.

BRAGA, M. M.; TEIXEIRA, R. M. R. Relato de uma experiência didática envolvendo o tratamento do eletromagnetismo no ensino médio com um enfoque conceitual. In: ENCONTRO ESTADUAL DE ENSINO DE FÍSICA, 1, 2006, Rio Grande do Sul. Atas [...] Porto Alegre, 2006.

CAMARGO, E. P.; NARDI, R. O emprego de linguagens acessíveis para alunos com deficiência visual em aulas de eletromagnetismo. Acta Scientiae, v. 10, n. 1, p. 97-118, 2008.

CHRISTIDOU, V. Greek students' science- related interests and experiences: gender differences and correlations. International Journal of Science Education, v. 28, n. 10, p. 1181-1199, 2006.

DAMASIO, F.; PEDUZZI, L. O. Para que ensinar ciência no século XXI?-reflexões a partir da filosofia de Feyerabend e do ensino subversivo para uma aprendizagem significativa crítica. Ensaio Pesquisa em Educação em Ciências, v. 20, e2951, p. 1-18, 2018.

DUARTE, N. Os conteúdos escolares e a ressureição dos mortos: contribuição à teoria histórico-crítica do currículo. Campinas: Autores Associados. 2016. 
ENGENESS, I.; LUND, A. Learning for the future: insights arising from the contributions of piotr galperin to the cultural-historical theory. Learning, Culture and Social Interaction, 2018.

ERTHAL, J. P. C.; GASPAR, A. Atividades experimentais de demonstração para o ensino de corrente alternada ao nível do ensino médio. Caderno Brasileiro de Ensino de Física, v. 23, n. 3, p. 345-359, 2006.

ESPINOSA, T.; ARAUJO, I. S.; VEIT, E. A. Crenças de autoeficácia em aprender Física e trabalhar colaborativamente: um estudo de caso com o método Team-Based Learning em uma disciplina de Física Básica. Revista Brasileira de Ensino de Ciência e Tecnologia, v. 12, n. 1, p. 29-54, 2019.

FÁVERO, M. H.; SOUSA, C. M. S. G. A resolução de problemas em física: revisão de pesquisa, análise e proposta metodológica. Investigações em Ensino de Ciências, v. 6, n. 2, p. 143-196, 2001.

FREIESLEBEN, F. B.; LODER, L. L.; BECKER, M. L. R. Uma metodologia de pesquisa sobre a construção de conhecimentos em circuitos elétricos lineares elaborada com base no método clínico piagetiano. Revista Brasileira de Pesquisa em Educação em Ciências, v. 17, n. 3, p. 1037-1060, 2017.

GASPAR, A. Cinquenta anos de ensino de física: muitos equívocos, alguns acertos e a necessidade do resgate do papel do professor. In: ENCONTRO DE FÍSICOS DO NORTE E NORDESTE, 15, 1997, Rio Grande do Norte. Atas [...] Natal: 1997, p. 1-13.

GILBERT, J. K.; BOULTER, C.; RUTHERFORD, M. Models in explanations, Part 1: Horses for courses? International Journal of Science Education, v. 20, n. 1, p. 83-97, 1998.

GONZALES, E. G.; ROSA, P. R. S. Aprendizagem significativa de conceitos de circuitos elétricos utilizando um ambiente virtual de ensino por alunos da Educação de Jovens e Adultos. Investigações em Ensino de Ciências, v. 19, n. 2, p. 477-504, 2014.

GRECA, I. M.; COSTA, S. S. C.; MOREIRA, M. A. Análise descritiva e crítica dos trabalhos de pesquisa submetidos ao III ENPEC. Revista Brasileira de Pesquisa em Educação em Ciências, v. 2, n. 1, p.73-82, 2002. 
GUERRA, A.; REIS, J. C.; BRAGA, M. Uma abordagem histórico-filosófica para o eletromagnetismo no ensino médio. Caderno Brasileiro de Ensino de Física, v. 21, n. 2, p. 224-248, 2004.

HAKE, R. R. Interactive-engagement versus traditional methods: a six-thousand-student survey of mechanics test data for introductory physics courses. American Journal of Physics, v. 66, n. 1, p. 64-74, 1998.

LABURÚ, C. E.; GOUVEIA, A. A.; BARROS, M. A. Estudo de circuitos elétricos por meio de desenhos dos alunos: uma estratégia pedagógica para explicitar as dificuldades conceituais. Caderno Brasileiro de Ensino de Física, v. 26, n. 1, p. 24-47, 2009.

LEITÃO, U. A.; FERNANDES, J. A.; LAGE, G. Investigação de perfis conceituais em uma atividade experimental sobre força magnética no ensino médio. Caderno Brasileiro de Ensino de Física, v. 35, n. 1, p. 290-315, 2018.

LOMPSCHER, J. Motivation and activity. European Journal of Psychology of Education, v. 14, n. 1, p. 11-22, 1999.

LOPES, D. P. M.; STEIN-BARANA, A. C. M.; MORENO, L. X. Construção de um guindaste eletromagnético para fins didáticos. Caderno Brasileiro de Ensino de Física, v. 26, n.1, p. 199-207, 2009.

MACÊDO, J. A.; DICKMAN, A. G.; ANDRADE, I. S. F. Simulações computacionais como ferramentas para o ensino de conceitos básicos de eletricidade. Caderno Brasileiro de Ensino de Física, v. 29, (n. esp.), p. 562-613, 2012.

MARTINS, A. A.; GARCIA, N. M. D. Ensino de Física e Novas Tecnologias de Informação e Comunicação: Uma Análise da Produção Recente. In: SIMPÓSIO NACIONAL DE ENSINO DE FÍSICA, 19, 2001, Manaus. Atas [...] Manaus: 2011.

MATOS, M. G.; VALADARES, J. O efeito da actividade experimental na aprendizagem da ciência pelas crianças do primeiro ciclo do ensino básico. Investigações em ensino de ciências, v. 6, n. 2, p. 227-239, 2001.

MONTEIRO, I. C. C.; GASPAR, A. Um estudo sobre as emoções no contexto das interações sociais em sala de aula. Investigações em Ensino de Ciências, v. 12, n. 1, p. 71-84, 2007. 
MONTEIRO, I. C. C. et al. As atividades de uma demonstração e a teoria de Vigotski: um motor elétrico de fácil construção e de baixo custo. Caderno Brasileiro de Ensino de Física, v. 27, n.2, p. 371-384, 2010.

MORAES, C. J. C.; OLIVEIRA, C. M.; GOLDSCHMIDT, A. I. Elaboração de estratégias de ensino e uso dos estatutos do conhecimento: os obstáculos na construção do conhecimento de Ciências-Física. Amazônia: Revista de Educação em Ciências e Matemáticas, v. 13, n. 28, p. 23-37, 2017.

MOREIRA, M. A. Teorias de Aprendizagem. São Paulo: Editora Pedagógica Universitária. 1999.

MOREIRA, M. M. P. C. et al. Contribuições do Arduino no ensino de física: uma revisão sistemática de publicações na área do ensino. Caderno Brasileiro de Ensino de Física, v. 35, n. 3, p. 721-745, 2018.

MÜLLER, M. G. et al. Implementação do método de ensino Peer Instruction com o auxílio dos computadores do projeto "UCA" em aulas de física do ensino médio. Caderno Brasileiro de Ensino de Física, v. 29 (n. esp.), p. 491-524, 2012.

OLIVEIRA, E. S.; REIS, N. A.; SILVA, E. L. Contextualização histórica dos estudos de Faraday sobre eletricidade e matéria: contribuições para o ensino de ciências. Revista de Ensino de Ciências e Matemática, v. 9, n.3, p. 87-105, 2018.

OLIVEIRA, V.; VEIT, E. A.; ARAUJO, I. S. Relato de experiência com os métodos ensino sob medida (Just-in-Time Teaching) e instrução pelos colegas (Peer Instruction) para o ensino de tópicos de eletromagnetismo no nível médio. Caderno Brasileiro de Ensino de Física, v. 32, n. 1, p. 180-206, 2015.

OLIVEIRA, V.; VEIT, E. A.; ARAUJO, I. S. Resolução de problemas abertos no ensino de física: uma revisão da literature. Revista Brasileira de Ensino de Física, v. 39, n. 3, e3042$17,2017$.

OSBORNE, J.; HENNESSY, S. Literature review in science education and the role of ICT: promise, problems and future directions. London: Futurelab Research. 2003.

PAULA, H. F. Fundamentos pedagógicos para o uso de simulações e laboratórios virtuais no ensino de ciências. Revista Brasileira de Pesquisa em Educação em Ciências, v. 17, n. 1, p. 75-103, 2017. 
PAULA, H. F.; TALIM, S. L. Uso coordenado de ambientes virtuais e outros recursos mediacionais. Caderno Brasileiro de Ensino de Física, v. 29, n. esp., p. 614-650, 2012.

PAZ, A. M. Atividades experimentais e informatizadas: contribuições para o ensino de eletromagnetismo. 2007. 228 f. Tese (Doutorado em Educação Científica e Tecnológica) Universidade Federal de Santa Catarina, Santa Catarina.

PEDROSO, L. S.; ARAÚJO, M. S. T. Aprendizagem significativa de conceitos de eletromagnetismo utilizando simulações interativas no ensino médio. Revista de Ensino de Ciências e Matemática, v. 3, n. 3, p. 512-523, 2012.

PEREIRA, A. A. G.; SILVA, C. C. Uma análise histórica da construção de significados físicos para o conceito de potencial vetor no eletromagnetismo clássico. Caderno Brasileiro de Ensino de Física, v. 34, n. 3, p. 798-822, 2017.

PEREIRA, A. P.; OSTERMANN, F. Sobre o ensino de física moderna e contemporânea: uma revisão da produção acadêmica recente. Investigações em Ensino de Ciências, v. 14, n. 3, p. 393-420, 2009.

PIEPER, F. C.; ANDRADE NETO, A. S. Evidências da emergência de drivers hiperculturais durante o aprendizado de conceitos de eletromagnetismo em alunos do Ensino Médio após a utilização de simulações computacionais. Acta Scientiae, v. 17, n. 3, 2015.

PINTO, J. A. F.; SILVA, A. P. B.; FERREIRA, É. J. B. Laboratório desafiador e história da ciência: um relato de experiência com o experimento de Oersted. Caderno Brasileiro de Ensino de Física, v. 34, n. 1, p. 176-196, 2017.

PIRES, C. F. D. J. S.; FERRARI, P. C.; QUEIROZ, J. R. D. O. A tecnologia do motor elétrico para o ensino de eletromagnetismo numa abordagem problematizadora. Revista Brasileira de Ensino de Ciência e Tecnologia, v. 6, n. 3, p. 29-45, 2013.

PONTONE JUNIOR, R.; PAULA, H. F. Um diagnóstico das publicações sobre o uso, no ensino de ciências, de simulações e laboratórios virtuais, entre 2009 e 2014. In: ENCONTRO NACIONAL DE PESQUISA EM EDUCAÇÃO EM CIÊNCIAS, 10, 2015, Águas de Lindóia. Atas [...] São Paulo, 2015. p. 1-8.

QUINTAS, M. J.; CARVALHO, P. S. Ensino interativo na abordagem de Eletricidade numa escola portuguesa. Caderno Brasileiro de Ensino de Física, v. 33, n. 3, p. 839-860, 2016. 
RESENDE, T. F.; FIREMAN, E. C. Explorando o conceito de magnetismo com alunos do curso de licenciatura em pedagogia a distância da UFAL: reflexões sobre o uso de experimentos didáticos no ensino de ciências da natureza nos anos iniciais da educação básica. Revista de Ensino de Ciências e Matemática, v. 5, n. 1, p. 76-91, 2014.

RIGON, A. J.; ASBAHR, F. S. F.; MORETTI, V. D. Sobre o processo de humanização. In: MOURA, M. O. (Ed.) A atividade pedagógica na teoria histórico-cultural. Campinas: Autores Associados, 2016. p. 15-50.

ROCHA, C. A. Elos entre a formação para o ensino de física e as novas tecnologias. Dissertação. 2001. 152f. (Mestrado em Engenharia de Produção) - Universidade Federal de Santa Catarina, Florianópolis.

ROCHA, C. H.; CATARINO, G. F. C. Kit experimental para ensino do eletromagnetismo: uma proposta de produto educacional. Revista de Educação, Ciências e Matemática, v. 9, n. $1,2019$.

ROSA, J. E.; DAMAZIO, A. O ensino de matemática no primeiro ano escolar: uma articulação entre a proposição gepapeana e a davydoviana. In: MOURA, M. O. (Ed.), Educação escolar e pesquisa na teoria histórico-cultural. São Paulo: Loyola, 2017. p. 153182.

SANTOS, R. C. M.; MACKEDANZ, L. F. O ensino de física para crianças: uma revisão bibliográfica. Acta Scientiae, v. 21, n. 3, p. 211-230, 2019.

SCARINCI, A. L.; PACCA, J. L. A. O conhecimento de física em um curso de formação contínua. Revista Brasileira de Pesquisa em Educação em Ciências, v. 10, n. 3, p. 51-70, 2010 .

SETLIK, J.; HIGA, I. Contribuições e dificuldades de práticas de leitura e escrita para ensinar e aprender física no ensino médio: reflexões à luz da cultura escolar. Revista Brasileira de Pesquisa em Educação em Ciências, v. 19, 2019.

SILVA, A. C. Eletromagnetismo e o anti-herói magneto: uma possível abordagem no ensino médio. Revista de Ensino de Ciências e Matemática, v. 3, n. 2, p. 125-135, 2012.

SILVA, A. C. Uma possível associação entre ciência e tecnologia no ensino de ciências: o exemplo do telefone. Revista Brasileira de Ensino de Ciência e Tecnologia, v. 6, n. 3, p. 126-147, 2013. 
SILVA JUNIOR, C. A. B. et al. Ensinando ciências físicas com experimentos simples no $5^{\circ}$ ano do ensino fundamental da educação básica. Revista Brasileira de Ensino de Ciência e Tecnologia, v. 12, n. 1, 2019.

SILVEIRA, F. L.; MARQUES, N. L. R. Motor elétrico de indução: "uma das dez maiores invenções de todos os tempos”. Caderno Brasileiro de Ensino de Física, v. 29, n. 1, p. 114$129,2012$.

SIQUEIRA, L. M.; TORRES, P. L. O ensino híbrido da eletricidade utilizando objetos de aprendizagem na engenharia. Caderno Brasileiro de Ensino de Física, v. 27, n. 2, p. 334$354,2010$.

SOUSA, C. M. S. G.; FÁVERO, M. H. Análise de uma situação de resolução de problemas de física, em situação de interlocução entre um especialista e um novato, à luz da teoria dos campos conceituais de Vergnaud. Investigações em Ensino de Ciências, v. 7, n. 1, p. 55-75, 2002.

SOUSA, C. M. S. G.; MOREIRA, M. A.; MATHEUS, T. A. M. A resolução de situaçõesproblema experimentais no campo conceitual do eletromagnetismo: uma tentativa de identificação de conhecimentos-em-ação. Revista Brasileira de Pesquisa em Educação em Ciências, v. 5, n. 3, p. 61-72, 2011.

SOUSA, J. M; MALHEIROS, A. P. S.; FIGUEIREDO, N. Desenvolvendo práticas investigativas no ensino médio: o uso de um objeto de aprendizagem no estudo da força de Lorentz. Caderno Brasileiro de Ensino de Física, v. 32, n. 3, p. 988-1006, 2015.

SPOHR, C. B.; GARCIA, I. K.; SANTAROSA, M. C. P. Identificando a evolução conceitual no ensino de eletromagnetismo, através de uma UEPS baseada num sistema de som automotivo gerador de energia. Investigações em Ensino de Ciências, v. 22, n. 3, 2017.

TEIXEIRA, J. N.; MURAMATSU, M.; ALVES, L. A. Um modelo de usina hidrelétrica como ferramenta no ensino de Física. Caderno Brasileiro de Ensino de Física, v. 34, n. 1, p. 248-264, 2017.

VERGNAUD, G. La théorie des champs concptuels. Récherches em Didactique des Mathématiques, v. 10, n. 23, p. 133-170, 1990.

VIGOTSKI, L. S. A formação social da mente. 4. ed. São Paulo, SP: Martins Fontes, 2002. 
VIGOTSKI, L. S. Pensamiento y habla. Trad. Alejandro Ariel González. Buenos Aires: Colihue, 2007.

WERTSCH, J. Mind as action. New York: Oxford University Press, 1998.

ZABALA, A. A prática educativa. São Paulo: Artmed, 2006. 